Journal of Sustainability Perspectives

\title{
BIM-Based Energy Optimization - Case study of High-Rise Building in Pakistan
}

\author{
Irbaz Hasan ${ }^{1, *}$, Syed Shujaa Safdar Gardezi , Usman Hussain ${ }^{3}$ \\ ${ }^{1,2,3}$ Department of Civil Engineering, Capital University of Science \& Technology (CUST), Islamabad Expressway, \\ Kahuta Road, Zone-V 44000 Islamabad, Pakistan \\ *corresponding author: mce183051@cust.pk
}

Article Info

Received:

15 March 2021

Accepted:

25 May 2021

Published:

1 June 2021

DOI:

https://doi.org/10.14710/j

sp.2021.11208

\begin{abstract}
The current work analyses the energy performance of a building at the early design and planning stage for sustainability. A multistory facility has been simulated in a virtual (3D) environment using the Building Information Modelling process. Energy analysis was performed using Autodesk Insight360 in terms of $\mathrm{kWh} / \mathrm{m}^{2} / \mathrm{yr}$. Sixteen (16) story building, has been assessed at its proposed location, at $8^{\circ}$ clockwise w.r.t true North. The study observed an annual consumption of $267 \mathrm{kWh} / \mathrm{m}^{2} / \mathrm{yr}$ which was further optimized by adopting different construction innovations. It has been highlighted that using virtual technology at the design stage of buildings can help to achieve an average annual energy saving of more than $50 \%$ thus supporting the goal for a sustainable future by accessing energy requirements at the early stage of design inception.
\end{abstract}

\section{Keyword:}

Building information modelling, energy analysis, energy optimization, architecture 2030 challenge.

\section{Introduction}

Sustainability is to maintain a level of natural resources that is necessary for the survival of life on earth [1] . For life's existence, infrastructure such as buildings is one of the basic needs which leads towards the construction industry. However, the construction sector has been considered the third principal contributor of GHG emission to the environment despite it being the backbone of infrastructure [2]. More than $70 \%$ of greenhouse gas is emitted from the buildings sector [3]. Energy utilization in the building sector is the basic concern for sustainable comfortable living [4]. Sustainable development encounters the essentials of the existing generation without compromising the ability of upcoming generations to meet their specific requirements [ $\underline{5}$ ]. Energy consumption was increasing over time and this trend in the world raised serious concerns about environmental impacts and other problems [6] . The global energy consumption trend 
unveiled that energy demand will grow up by over one-third by 2035 []]. Fig. 1 provides an overview of project energy demand.

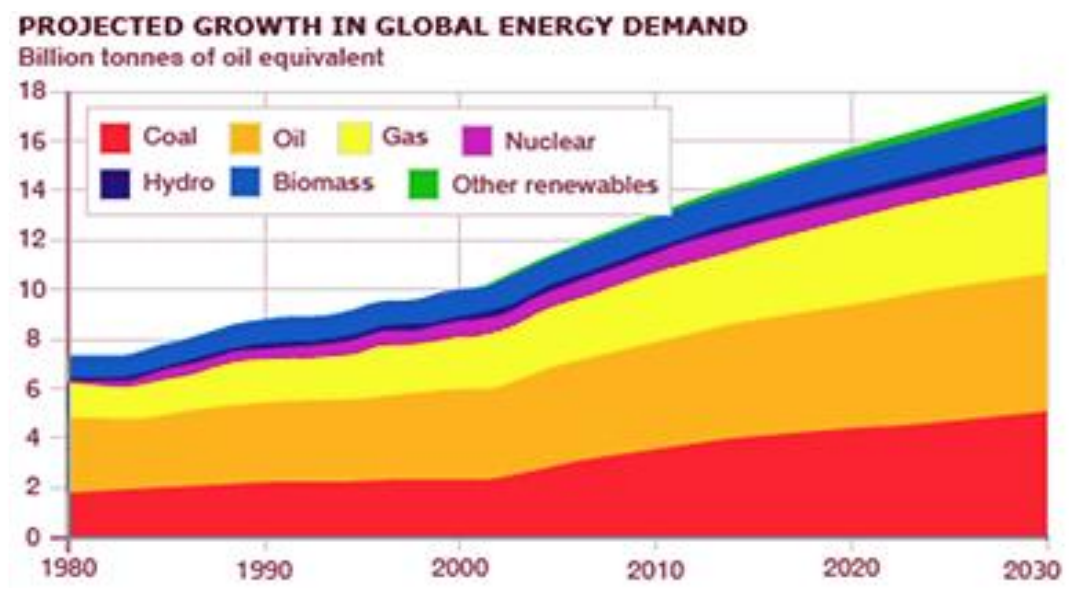

Figure 1. Increase in Global Energy Demand [] $]$

Besides many other solutions for sustainability, the implementation of virtual innovations, Building Information Modeling (BIM), an early stage of building design inceptions can provide valuable support for energy assessments. The idea of utilizing BIM refers to the modeling technology \& related set of procedures to produce, communicate, and analyze the structural models [9]. New buildings and renovations in the construction industry can carbon-neutral as envisioned by the ARCHITECTURE 2030 challenge. All this required to avoid the environmental impacts of the building sector on climate resulting in greenhouse gas emissions, rise in temperature and sudden environmental changes, etc. [10]

By using BIM for high rise buildings, the maximum sustainability concerns in terms of energy by optimizing the energy performance of high-rise building can be investigated. Such energy analysis can address the issues related to energy optimization.

\section{Methodology}

The scientific approach adopted for the achievement of the proposed objectives is illustrated in Fig. 2. After the selection of the case study, the virtual model of the building was developed using Revit. The 3D model was then transformed into the energy model to perform the energy analysis in Insight 360. Two iterations were performed, one for original building attributes and the other with modifications for optimization. Based on the results, a comparative analysis was performed to observe the energy differences achieved.

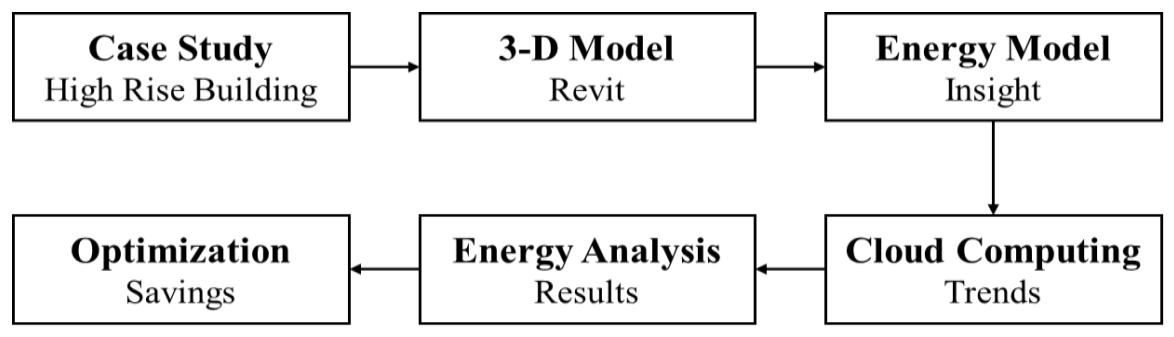

Figure 2. Workflow 


\subsection{Case Study}

A sixteen-story building located in the capital city of Pakistan has selected and been analyzed. The developed 3-D model is presented in Fig. 3.

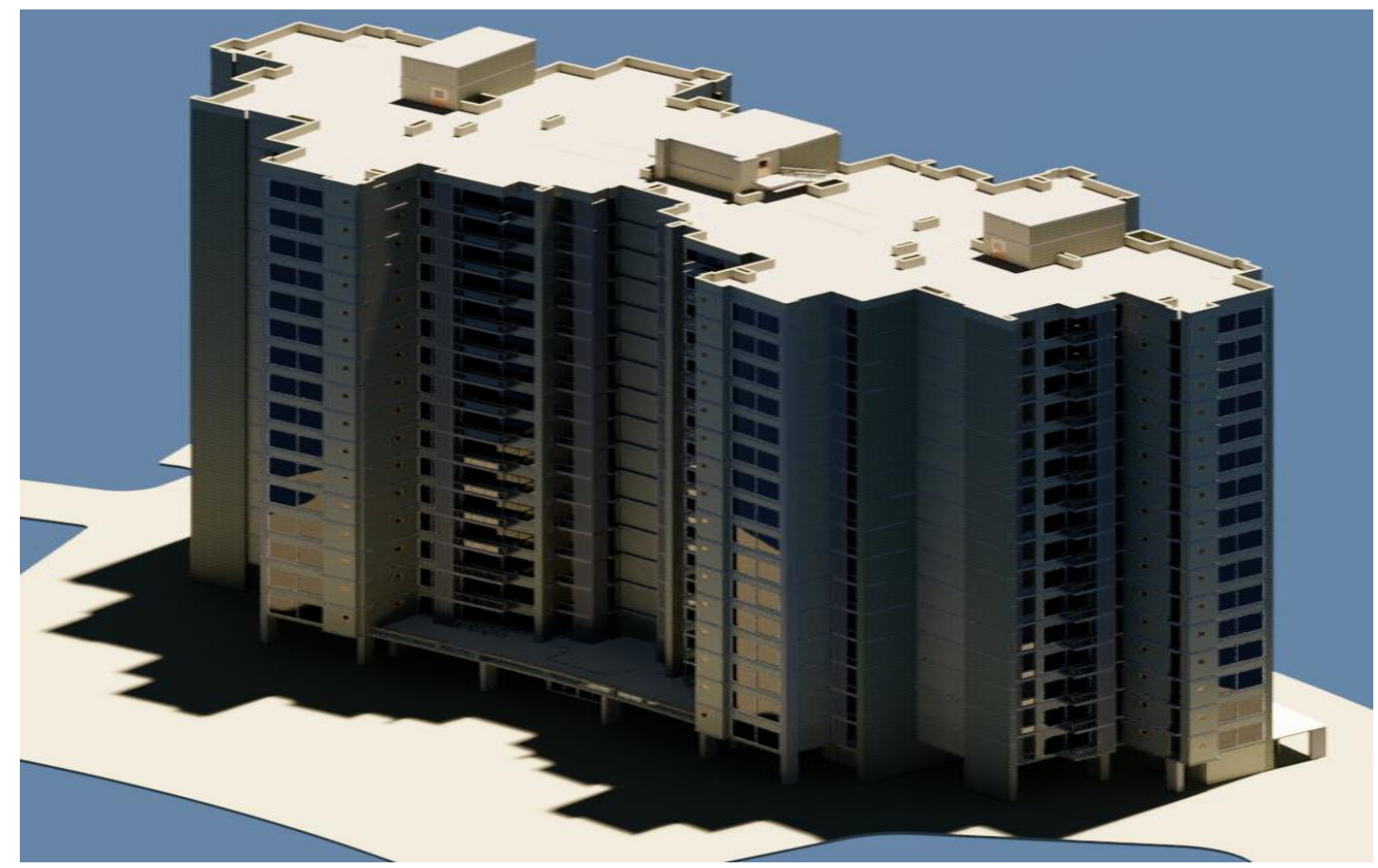

Figure 3. Perspective Views of 3-D Virtual Model

\subsection{Energy Analysis}

3-D virtual BIM model was assessed for energy consumption using Autodesk Insight360 at $8^{\circ}$ clockwise from True North, Fig. 4. At this point, the average energy of 267 $\mathrm{kWh} / \mathrm{m}^{2} / \mathrm{yr}$ was observed for the simulated model. The upper and lower limit of energy consumption were 1004 and $38 \mathrm{kWh} / \mathrm{m}^{2} / \mathrm{yr}$, respectively. ASHRAE 90.1 benchmark value was $290 \mathrm{kWh} / \mathrm{m}^{2} / \mathrm{yr}$ and Architecture 2030 goal for a sustainable future was 110 $\mathrm{kWh} / \mathrm{m}^{2} / \mathrm{yr}$. However, our achieved energy of $267 \mathrm{kWh} / \mathrm{m}^{2} / \mathrm{yr}$ was higher than Architecture 2030 goal and required to be lowered for a sustainable future.
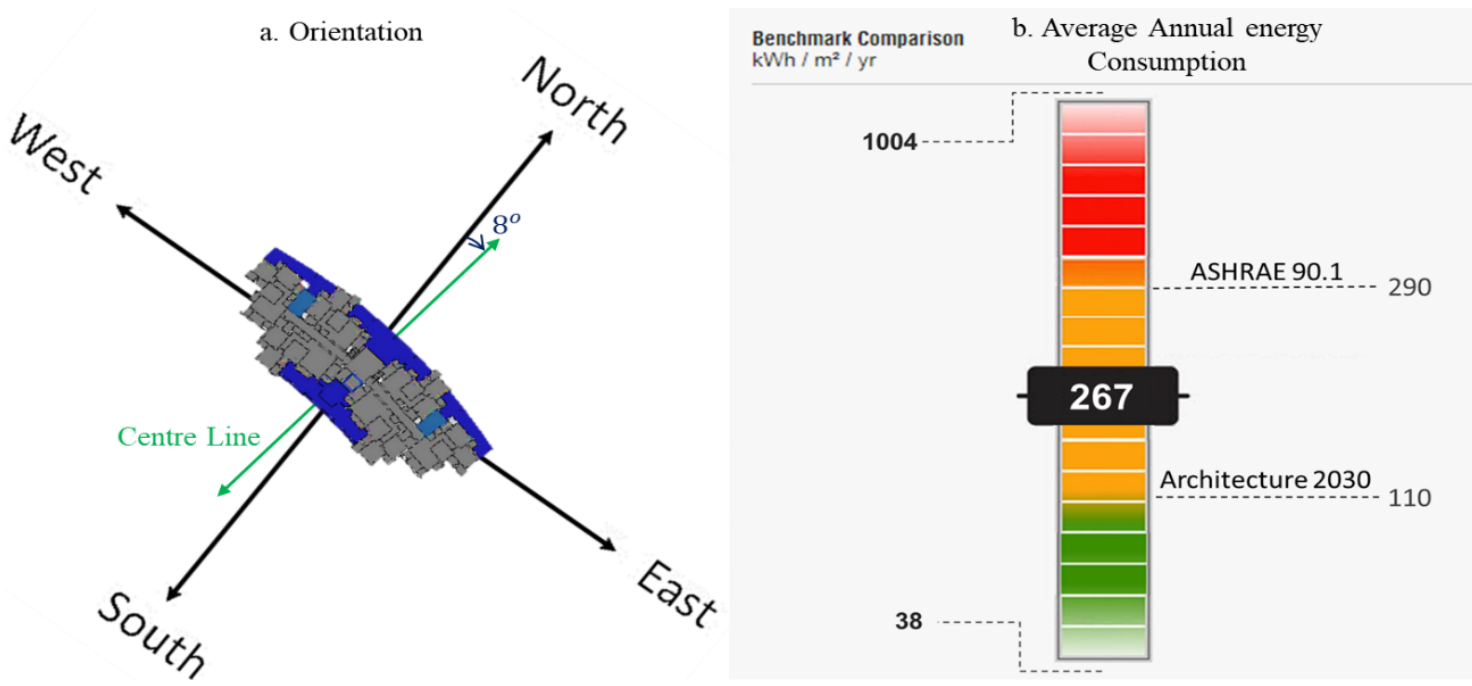

Figure 4. Average Annual Energy Consumption at the original location of the building 


\subsection{Energy Optimization}

After the energy analysis, optimization of this orientation was done based on the guidelines and factors mentioned below in Table 1 . The optimization is done according to the actual building features. The values were chosen from the available range of settings to achieve the ARCHITECTURE 2030 goal as it supports carbon neutrality. So, to be sustainable development, our energy consumption value should be lower to support the carbon-neutral aim.

Table 1. Optimization Elements

\begin{tabular}{|c|c|c|}
\hline Factors & Settings & $\begin{array}{l}\text { Optimized } \\
\text { Settings }\end{array}$ \\
\hline Benchmark & $267 \mathrm{kWh} / \mathrm{m}^{2} / \mathrm{yr}$ & $97 \mathrm{kWh} / \mathrm{m}^{2} / \mathrm{yr}$ \\
\hline Orientation & $45^{\circ}$ & $45^{\circ}$ \\
\hline \multicolumn{3}{|l|}{ Window to Wall Ratio (WWR) } \\
\hline South & \multirow{4}{*}{$95 \%$ to $0 \%$} & $16 \%$ \\
\hline North & & $14 \%$ \\
\hline West & & $29 \%$ \\
\hline East & & $20 \%$ \\
\hline \multicolumn{3}{|l|}{ Window Shades } \\
\hline \multicolumn{3}{|l|}{ South } \\
\hline North & \multirow{3}{*}{$1 / 6$ to $2 / 3$ Win Height } & \multirow{3}{*}{ 1/2 Win Height } \\
\hline West & & \\
\hline East & & \\
\hline Wall Construction & Uninsulated to R13 + R10 Metal & BIM \\
\hline Roof Construction & Uninsulated to BIM & BIM \\
\hline Infiltration & $2.0 \mathrm{ACH}$ to $0.17 \mathrm{ACH}$ & $0.285 \mathrm{ACH}$ \\
\hline Lighting Efficiency & $20.45 \mathrm{~W} / \mathrm{m}^{2}$ to $3.23 \mathrm{~W} / \mathrm{m}^{2}$ & $7.53 \mathrm{~W} / \mathrm{m}^{2}$ \\
\hline \multirow{2}{*}{ Daylighting \& Occupancy Controls } & None - Daylighting \& Occupancy & Occupancy \\
\hline & Controls & Controls \\
\hline Plug Load Efficiency & $29.99 \mathrm{~W} / \mathrm{m}^{2}$ to $6.46 \mathrm{~W} / \mathrm{m}^{2}$ & $6.46 \mathrm{~W} / \mathrm{m}^{2}$ \\
\hline Operating Schedule & $24 / 7$ to $12 / 5$ & $12 / 6$ \\
\hline PV - Panel Efficiency & $16 \%$ to $20.4 \%$ & $18.60 \%$ \\
\hline PV - Pay Back Limit & $10 \mathrm{yr}$ to $30 \mathrm{yr}$ & $30 \mathrm{yr}$ \\
\hline PV - Surface Coverage & $0 \%$ to $90 \%$ & $60 \%$ \\
\hline
\end{tabular}

Actual Window to wall ratio was chosen for each side of the building according to the design features i.e., $16 \%$ for the south, $14 \%$ for the north, $29 \%$ for the west, and $20 \%$ for the east. Among the available setting, 1/2 Win Height setting was applied for window shades. Wall and roof construction were according to building specifications which were convention block walls insulated by plaster and reinforced cement concrete slab for the roof as BIM settings. Infiltration rate according to actual openings of the building was applied. Lighting and Plug load efficiency were 7.53 and $6.46 \mathrm{~W} / \mathrm{m}^{2}$, respectively. The operating 
schedule was chosen as conventional six days a week and 12 hours a day. Panel efficiency was nearly about $20 \%$ with a payback period of 30 years and surface coverage of $60 \%$.

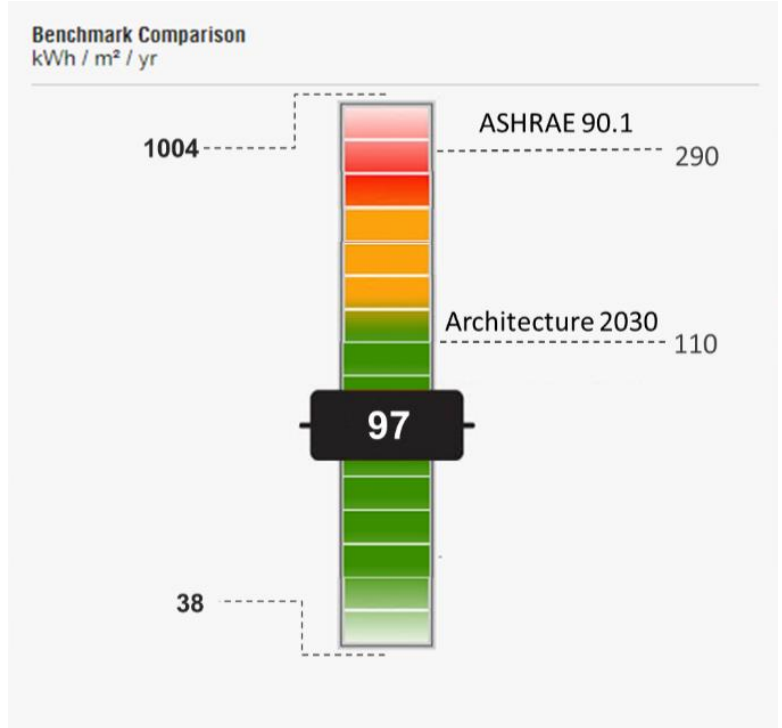

Figure 5. Energy Optimization

Fig. 5 illustrates the energy utilization decrease with the optimization factors. A critical analysis observed HVAC, lighting efficiency and window shades were responsible for major energy consumption among these sixteen factors. Other key factors are window to wall ratio, window shades, plug load efficiency and operating schedule. Window to wall ratio of Eastern wall and window shades are collectively reducing the $30 \mathrm{kWh} / \mathrm{m}^{2} / \mathrm{yr}$.

In actual model analysis, the energy consumption does not meet the ARCHITECTURE 2030 benchmark. However, after incorporating the optimized options, it reduced and settled down to the green zone. The green color indicated that the optimized energy of 97 $\mathrm{kWh} / \mathrm{m}^{2} / \mathrm{yr}$ has now satisfied the criteria of a carbon-neutral building. An overall annual energy saving of $170 \mathrm{kWh} / \mathrm{m}^{2} / \mathrm{yr}$ has lowered the value below the 110 milestones. In other words, adopting the optimizations measures, mentioned in table 1, in the actual field can help to support objectives of ARCHITECTURE 2030 i.e., a carbon-neutral environment. The study expects that adopting proactive approaches at design inception and decision-making stages can help to achieve a sustainable future in terms of energy usage.

\section{Conclusion}

The scope was limited to a case study of a multistorey building and only an operational phase was undertaken in this research work. The virtual model of the selected case study was developed in BIM and transformed into an energy model using Insight. The study aimed to achieve optimization in the energy consumption patterns thus supporting the ARCHITECTURE 2030 challenge. The following conclusions have been made :

- More than $60 \%$ reduction in overall utilization can be achieved using this framework in the early stage of design during the life cycle of a building project.

- By incorporation certain innovative attributes, the average annual energy consumption was optimized as $97 \mathrm{kWh} / \mathrm{m}^{2} / \mathrm{yr}$, a value less than the Architecture 2030 challenge to go green for sustainability 
- The optimal energy consumption design will help to improve the development of sustainable buildings in terms of energy consumption.

\section{Acknowledgments}

The authors would like to thank Capital University of Science and Technology, BIM Center of Excellence and the organizations for their support to complete this research work.

\section{References}

1. Arora, N., Environmental Sustainability-necessary for survival. Environmental Sustainability, 2018. 1.

2. Liu, S., X. Meng, and C. Tam, Building information modeling based building design optimization for sustainability. Energy and Buildings, 2015. 105: p. 139-153.

3. Gao, H., C. Koch, and Y. Wu, Building information modelling based building energy modelling: A review. Applied Energy, 2019. 238: p. 320-343.

4. Cho, C.S., D. Chen, and S. Woo, Building information modeling (BIM) - Based design of energy efficient buildings. Proceedings of the 28th International Symposium on Automation and Robotics in Construction, ISARC 2011, 2011: p. 1079-1084.

5. Isopescu, D., The impact of green building principles in the sustainable development of the built environment. IOP Conference Series: Materials Science and Engineering, 2018. 399: p. 012026.

6. Li, B. and R. Yao, Urbanisation and its impact on building energy consumption and efficiency in China. Renewable Energy, 2009. 34(9): p. 1994-1998.

7. Healy, N., J.C. Stephens, and S.A. Malin, Embodied energy injustices: Unveiling and politicizing the transboundary harms of fossil fuel extractivism and fossil fuel supply chains. Energy Research \& Social Science, 2019. 48: p. 219-234.

8. Lane, J.-E., Global Warming is an Energy Conundrum. Earth Science Research, 2018. 7: p. 1.

9. Tushar, Q., et al., Optimizing the energy consumption in a residential building at different climate zones: Towards sustainable decision making. Journal of Cleaner Production, 2019. 233: p. 634-649.

10. Huang, L., et al., Carbon emission of global construction sector. Renewable and Sustainable Energy Reviews, 2017. 81. 